\title{
Erratum to: Youth as Architects of Social Change
}

\author{
Sheri Bastien, Halla B. Holmarsdottir
}

(C) The Author(s) 2017

S. Bastien, H.B. Holmarsdottir (eds.), Youth as Architects of Social Change, https://doi.org/10.1007/978-3-319-66275-6

The original version of the book contained an error which has been corrected.

The chapter level copyright year has been updated as 2017 throughout the book.

The updated original online version for this book can be found at https:// doi.org/10.1007/978-3-319-66275-6 